\title{
Moving from a blame culture to a learning culture in the NHS
}

\author{
Emeritus Professor Alan Glasper, from the University of Southampton, discusses the latest initiative from \\ Secretary of State for Health, Jeremy Hunt, to foster a culture of learning from past mistakes
}
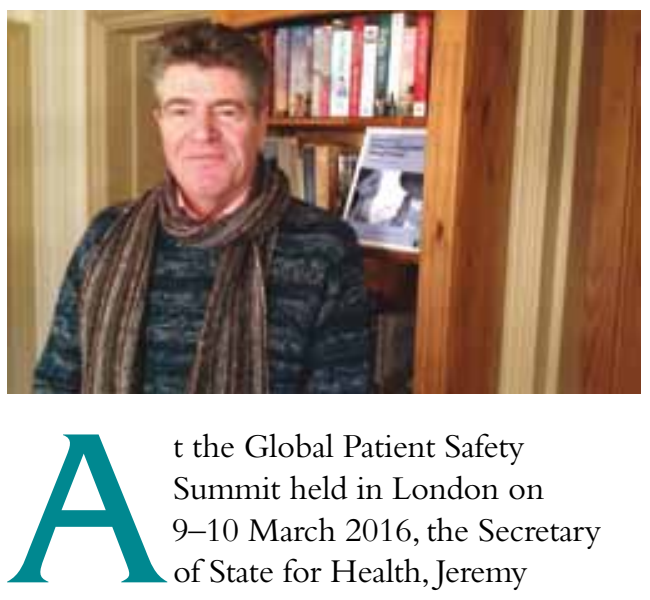

Hunt, gave a speech in which he committed the Government to prioritising patient safety in the NHS through three important announcements (Department of Health (DH) and Hunt, 2016a).

Delegates at the summit included health ministers and senior expert clinicians from across the world. In his speech to summit delegates the Health Secretary first announced the formation of an independent Healthcare Safety Investigation Branch (HSIB) and legal protection for whistleblowers who expose and escalate information pertinent to clinical and other mistakes. This will protect them from potential retribution in the work place.

HSIB will commence operations in April 2016 and will offer support and guidance to NHS organisations on how to conduct investigations, in addition to conducting its own (GOV.UK, 2016).

The primary aim of HSIB will be to fully investigate any patient safety incident that is referred by taking a non-punitive approach. Its practices and recommendations will be intended for:

\section{'Learning and improvement, not to find fault, attribute blame or hold people to account.'}

(GOV.UK, 2016)

Second, the Health Secretary announced that NHS trusts and foundation trusts will be publicly ranked on their openness and transparency under a new 'Learning from mistakes league' launched by Monitor and the NHS Trust Development Authority (TDA) (Monitor and NHS TDA, 2016. It should also be noted that from April 2016 Monitor and NHS TDA have merged, along with a number of other groups including the National Reporting and Learning System (NRLS), to become a new body entitled NHS Improvement (NHS Improvement, 2016).

According to Mike Durkin at NHS England, learning from mistakes does save lives and to fully learn from mistakes the creation of a culture with openness and transparency at its heart is fundamental. This new organisation believes that by informing NHS trusts of how well they are performing compared with other trusts, this will drive up safety standards.

Third, the Health Secretary has announced the introduction, from April 2018, of medical examiners to independently review and confirm the cause of all deaths ( $\mathrm{DH}$ and Hunt, 2016b).

This was anticipated as independent medical examiners were first recommended following the 2005 inquiry into the murders of patients by Dr Harold Shipman (DH and Hunt, 2016b). and following Sir Robert Francis's inquiry into the scandal at the MidStaffordshire NHS Foundation Trust (Francis, 2013). The Health Secretary is optimistic that the introduction of medical examiners will improve the ability of the NHS to learn from unexpected or avoidable deaths.

\section{Background}

In his speech, the Health Secretary reminded delegates in the NHS there are potentially a high number of avoidable deaths, and he is anticipating that the NHS will transcend from a historical blame culture to a learning culture. He aspires to change the UK health service as it evolves into an organisation built on openness to become the safest healthcare system in the world. He believes that much progress has already been made in the intervening years since the public became aware of the catastrophic failures of the Mid-Staffordshire NHS Foundation Trust. The Health Secretary's aspiration for an NHS that can offer 24-hour, 7-days-a-week safe care can only occur if the current NHS stops its quick-fix blame culture where a succession of senior executives fall on their metaphorical swords and instead accepts and acknowledges that sometimes serious mistakes can be made by hardworking and loyal patient advocates from a variety of healthcare professions.

The Care Quality Commission (CQC) already examines safety when conducting its inspections of hospitals. Hospital inspectors and specialist advisors gather evidence from 5 key areas when seeking to assure themselves that a care organisation is safe.

The first area considers whether lessons are learned and improvements made when things go wrong. The second looks at the track record on safety. In the context of these first two aspects of safety, data will be gathered on the safety performance of an institution over time. To illuminate this, CQC staff will investigate any 'never events' (i.e. patient safety incidents that should not have occurred if the available preventive measures had been implemented) and staff at the institution will be interviewed to ascertain if they understand their roles and responsibilities to raise and escalate concerns about patient safety including 'near misses'. Staff will also be questioned about their roles in implementing the duty of candour. It is how the institution behaves when things go wrong that interests the CQC, and CQC staff will seek reassurances that lessons learned from safety incidents are cascaded appropriately to prevent reccurrence. The 
CQC also seeks evidence of the use of patient safety thermometers such as early warning score protocols and the use of SBAR (Situation, Background, Assessment and Recommendation technique) (http:// tinyurl.com/2dhymd2) and other patient safety models.

A key area investigated by the CQC when examining safety is the effectiveness of mandatory training in safety systems, processes and practices. This is especially true of safeguarding, where evidence to show that vulnerable service users are protected will be gathered. The CQC also gathers data on the management of cleanliness, infection control and hygiene.

The third key area the CQC considers is the assessment and the management of patient risk. This includes staffing levels and the appropriate rostering of members of the multidisciplinary team. In this situation inspectors will compare actual staffing numbers with those recommended by bodies such as the Royal College of Nursing (RCN) who have formulated safe staffing ratios for different areas of care, for example the care of children and young people (RCN, 2013)

Given that nurses make up the largest component of the NHS workforce it is not surprising that the CQC examines nurse staffing levels in significant detail as a measure of patient safety. In his written submission of evidence to the health and social care committee of the National Assembly for Wales Consultation on the Safe Nurse Staffing Levels (Wales) Bill, Professor Peter Griffiths, Chair of Health Services Research at the University of Southampton, highlighted the extensive evidence that shows that lower levels of nurse staffing in hospitals are associated with poorer patient outcomes. (Griffiths et al, 2016).

The final area of safely investigated in any CQC inspection of a hospital is how well the institution is prepared to deal with potential risks to the service and if these risks are anticipated and planned for in advance.

\section{Discussion}

As part of his plan for a safer NHS, the Health Secretary announced that:

- The General Medical Council and Nursing and Midwifery Council will amend their guidance for registrants so that when a member is honest about a mistake they have made and apologises, a subsequent professional tribunal will award them credit for that admission, but if that registrant fails to do so they will be more likely to receive a more serious sanction

- The new NHS Improvement will require all NHS trusts to publish a charter for openness and transparency so that staff have clear expectations of how they will be treated if they witness clinical errors

- NHS England will work with the Royal College of Physicians to develop a standardised method for reviewing the records of patients who have died in hospital

- England will become the first country in the world to publish estimates by hospital trust of avoidable mortality rates. These data will be non-comparable because trusts will have different methodologies for collecting these data. (DH and Hunt 2016b).

The Health Secretary said that an estimated 1 million patients die in hospitals across the world every year owing to avoidable clinical incidents. Although he admitted that these data cannot be verified because of the variability in reporting standards across the world, were it to be of the scale estimated it would put deaths from clinical incidents in the same league as deaths from road accidents (DH and Hunt, 2016a).

He also cited the work of Hogan et al (2015) who investigated the avoidability of hospital deaths in England. This seminal retrospective case record review suggested that $3.6 \%$ of hospital deaths have a $50 \%$ or more chance of being avoidable (Hogan et al, 2015) which represents a potential of 150 avoidable deaths every week (DH and Hunt, 2016a).

\section{Conclusion}

The Health Secretary sees that profound culture change is necessary to ensure that the NHS completes its journey in making the changes from a blame culture to a learning culture. It will be through the range of measures being introduced that will lead to the intelligent transparency needed to make the changes necessary for improved patient safety. In addition, the CQC Chief Inspector of Hospitals, Sir Mike Richards, intends to incorporate a range of indicators into hospital inspections including staff survey measures of how supported frontline staff feel if they raise safety concerns and whether staff feel able to contribute towards improvements in their work place (DH and Hunt, 2016a).

The Health Secretary has admitted that safer care requires more NHS resources, but points out that unsafe care is even more expensive costing the NHS up to $£ 2.5$ billion a year, attributed to longer hospital stays, repeat visits and litigation (DH and Hunt, 2016a). Nurses and other health professionals will welcome these proposals which offer service users the safe high-quality care they deserve. BJN

Department of Health, Hunt J (2016a) From a blame culture to a learning culture. [Speech transcript] 3 March. http://tinyurl.com/j4cjlao (accessed 5 April 2016)

Department of Health, Hunt J (2016b) Plans to end the cover-up culture in the NHS. 9 March. http://tinyurl. com/zzxwoyg (access 5 April 2016)

Francis R (2013) The Mid Staffordshire NHS Foundation Trust Public Enquiry. http://tinyurl.com/p2ebw82 (accessed 5 April 2016)

Griffiths P (2014) Consultation on the Safe Nurse Staffing Levels (Wales) Bill: written submission of evidence to the Health and Social Care Committee. http://tinyurl. com/zn6q6yd (accessed 5 April 2016)

Griffiths P, Ball J, Murrells T, Jones S, Rafferty AM (2016) Registered nurse, healthcare support worker, medical staffing levels and mortality in English hospital trusts: a cross-sectional study. BMJ Open 6(2): e008751. doi: 10.1136/bmjopen-2015-008751

GOV.UK (2016) Healthcare Safety Investigation Branch (HSIB) Expert Advisory Group. http://tinyurl.com/ h4zzkhv (accessed 5 April 2016)

Hogan H, Zipfel R, Neuburger J, Hutchings A, Darzi A, Black N (2015) Avoidability of hospital deaths and association with hospital-wide mortality ratios: retrospective case record review and regression analysis. BMJ: h3239. doi: 10.1136/bmj.h3239

Monitor, NHS Trust Development Agency (2016) New league launched to encourage openness in the NHS. http://tinyurl.com/zotybwa (accessed 5 April 2016)

NHS Improvement (2016) Who we are. http://tinyurl. com/jozwxvy (accessed 5 April 2016)

Royal College of Nursing (2013) Defining staffing levels for children's and young people's services. RCN, London

\section{KEY POINTS}

- Secretary of State for Health, Jeremy Hunt, has committed to prioritising patient safety in the NHS

- Legal protection will be given to whistleblowers who expose and escalate information pertinent to mistakes and will protect them from potential retribution in the work place

- The Nursing and Midwifery Council will soon amend its guidance to registrants so that when a member is honest about a mistake they have made and apologises, a subsequent professional tribunal will award them credit for that admission

- Evidence shows that lower levels of nurse staffing in hospitals are associated with poorer patient outcomes 